Mr Velibor Tomić Kruševac

Mr Dragan Nikolić, kapetan I klase SC ABHO, Kruševac

\section{ISPITIVANJE SORPCIONIH KARAKTERIS- TIKA AKTIVNIH UGLJEVA NA PARE BENZINA}

UDC: $628.512-039.7 .912: 614.894$

Rezime:

Benzin ima veoma široku primenu, međutim, kao i njegova isparenja deluje toksično na ljudski organizam. Za zaštitu organa za disanje, radnu $i$ životnu sredinu veoma je važna upotreba aktivnog uglja. U radu je prikazano ispitivanje sorpcionih karakteristika damacih aktivnih ugljeva na pare benzina.

Ključge reči: adsorpcija, aktivni ugalj, vreme zaštitnog dejstva, kriva probijanja, izoterma adsorpcije

\title{
INVESTIGATION OF ACTIVATED CARBON SORPTION CHARACTERISTICS ON PETROL VAPOUR
}

Summary:

Petrol is urdely applicated although it (especially its vapours) has toxical effects on human organism. The activated carbon application is very important for the protection of respiratory system, work environment and environment in general. Domestic activated carbons and their sorption characteristics were investigated an petrol vapour.

Key words: adsorption, activated carbon, protective effects time, penetration curve, adsorption isotherm.

\section{Uvod}

Benzin kao i pare benzina deluju toksično na ljudski organizam.

Aktivni ugalj je jedan od najboljih adsorbenata za zaštitu organa za disanje, radne i životne sredine. Poseduje veoma razvijenu poroznu strukturu, a dobija se od koštica kokosa ili šljiva, od drveta i sl.

Filteri na bazi aktivnog uglja vrlo su efikasni pri radu sa benzinima u određenim postrojenjima i radionicama. $\mathrm{Na}$ osnovu karakteristika aktivnog uglja i eksperimentalnih podataka moguće je odrediti geometriju sloja aktivnog uglja potrebnog za zaštitu organa za disanje i za zaštitu radne i životne sredine $u$ svim uslovima rada sa benzinom.

U radu su izvršena ispitivanja sorpcionih karakteristika ugljeva domaće proizvodnje na pare benzina radi korišćenja podataka $u$ matematičkim modelima dinamike adsorpcije, i za proračun geometrije sloja aktivnog uglja.

\section{Toksične osobine benzina}

Zavisno od svog porekla, benzin može da sadrži različite količine cikličnih $i$ aromatičnih ugljovodonika $i$ druge toksične produkte. 
Ima široku primenu $\mathrm{u}$ industriji, a naročito se koristi kao pogonsko gorivo.

Benzin ima jak afinitet prema lipoidima i izaziva tipično narkotične pojave. Toksičnost benzina zavisi od njegove isparljivosti, a lako isparljivi benzini otrovniji su od teško isparljivijih viših frakcija.

Maksimalno dopuštena koncentracija za neetiliziran benzin $u$ vazduhu iznosi $125 \mathrm{ppm}$.

Akutno trovanje benzinom može nastati i kada su pare benzina prisutne $\mathrm{u}$ atmosferi. Ako otrovani ostaje $\mathrm{u}$ takvoj atmosferi može doći i do smrtnog ishoda. Prvi simptomi hroničnog trovanja su nervna neuravnoteženost, pojava malaksalosti i mišićne slabosti, pospanost ili nesanica, anemija i tzv. sopijenost benzinom". Kasnije se javlja bol u grudima, težak i mučan kašalj, krvava mokraća, a može doći do oboljenja bronhija, kao i pneumonije.

\section{Eksperimentalni deo}

Ispitivanje izotermi adsorpcije $\mathrm{i}$ krive probijanja para benzina na aktivnom uglju $\mathrm{R}$ (aktivirani retortni bukov ugalj) i K (KCS aktivirana ugljenisana kokosova ljuska) obavljeno je u laboratoriji "TRAJAL" korporacije $\mathrm{u}$ Kruševcu. Aktivni ugalj $\mathrm{R}$ i K serijski su proizvod sa karakteristikama prikazanim u tabeli 1 .

Benzin koji je korišćen kao adsorptiv proizvod je Rafinerije nafte Pančevo, pod trgovačkim nazivom $\mathrm{S}$.

Šema aparature na kojoj su sprovedena ispitivanja izoterme adsorpcije od relativnih pritisaka (koncentracija) para benzina $\mathrm{u}$ struji vazduha prikazana je na slici 1.

Komprimovani vazduh se prethodno prečišćava kroz filter-adsorber (FA1), redukuie u reducir-stanici, da bi nakon toga bio sušen $u$ ispiralicama (I1 i I2) sa koncentrovanom sumpornom kiselinom i silikagelom (KS 1). Nakon podešavanja protoka na roto-

Karakteristike aktivnih ugljeva

Tabela 1

\begin{tabular}{|c|c|c|}
\hline Karakteristike & $\begin{array}{c}\text { Granulisani aktivni } \\
\text { ugalj } R\end{array}$ & $\begin{array}{c}\text { Aktivni ugalj u zrnu } \\
(0,5 \text { do } 2,5 \mathrm{~mm}) \mathrm{KCS}\end{array}$ \\
\hline Vlažnost & $5 \%$ & $5 \%$ \\
\hline Sadržaj pepela & 7 do $9 \%$ & 4 do $5 \%$ \\
\hline $\begin{array}{l}\text { Indeks benzina merenjem } \\
\text { adsorpcione mase pare }\end{array}$ & $\min 33 \%$ & $\min 35 \%$ \\
\hline Indeks benzina $\mathrm{u}$ praksi & 35 do $36 \%$ & $\min 42$ do $45 \%$ \\
\hline Jodni broj AWWA (1) & 950 do $1050 \mathrm{mg} / \mathrm{g}$ & 1150 do $1200 \mathrm{mg} / \mathrm{g}$ \\
\hline Specifična površina BET & $1000 \mathrm{~m}^{2} / \mathrm{g}$ & 1150 do $1200 \mathrm{~m}^{2} / \mathrm{g}$ \\
\hline $\mathrm{pH}$ vrednost & 10 & 9 do 10,5 \\
\hline Mehanička otpornost & 74 do $75^{\circ} \%$ & - \\
\hline Zapremina mikropora & 一 & 0,40 do $0,45 \mathrm{~cm}^{3} / \mathrm{g}$ \\
\hline Nasipna masa & 380 do $400 \mathrm{~kg} / \mathrm{m}^{3}$ & 430 do $480 \mathrm{~kg} / \mathrm{m}^{3}$ \\
\hline
\end{tabular}


metru (R) na 0,5 do $1,0 \mathrm{dm}^{3} / \mathrm{min}$, vazduh se deli u dve grane u kojima se dodatno suši kroz sloj silikagela (KS2 i KS3). Kontrola protoka u granama ostvaruje se meračima protoka sa ka- pilarima (K1 i K2) koji su prethodno izbaždareni. Raspodeljena struja vazduha u dve grane ulazi u termički regulisano vodeno kupatilo (TRVK) gde strujanjem kroz spiralne izmenjivače

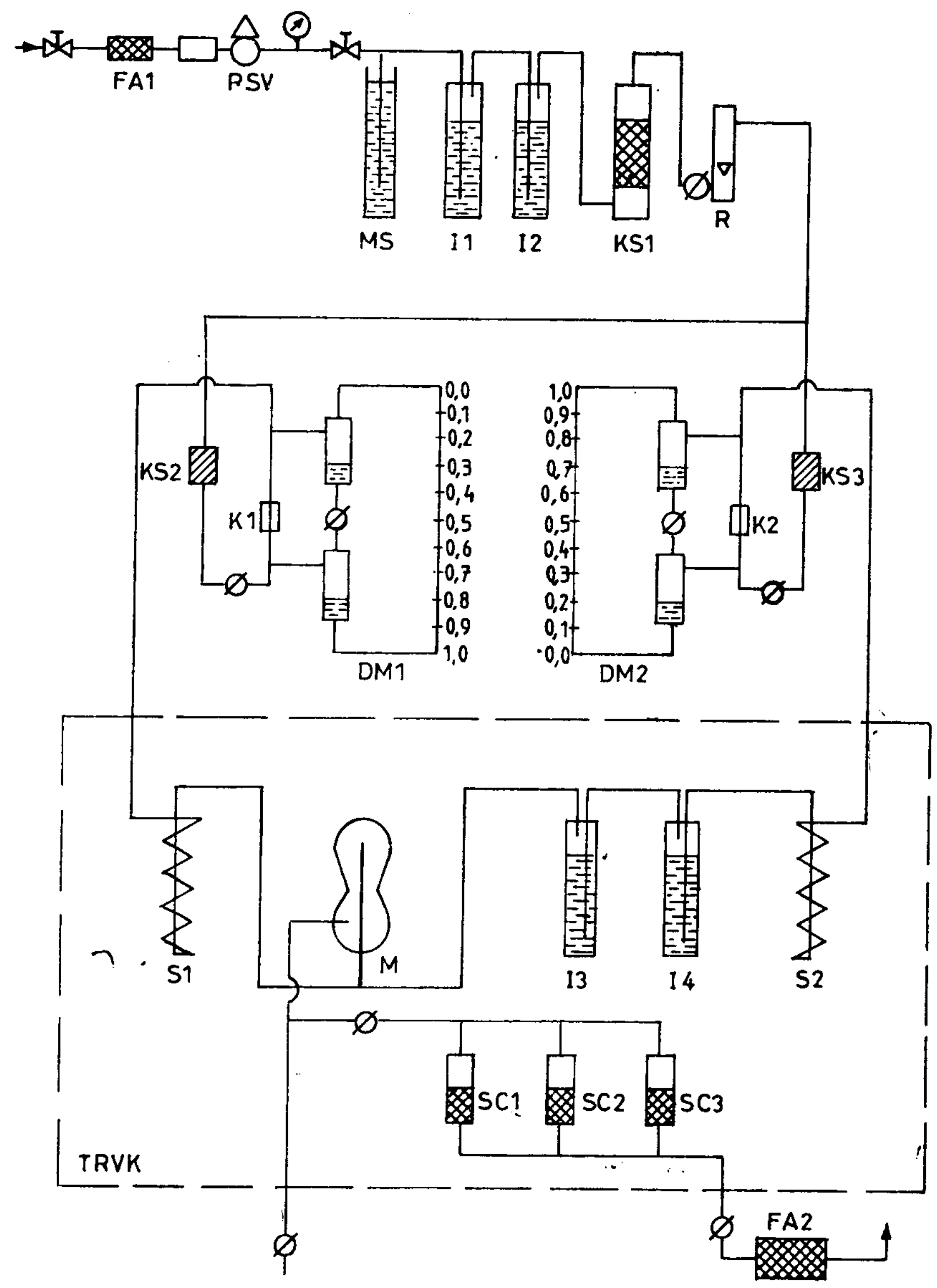

Sl. 1 - Aparatura za ispitivanje izoterme adsorpcije na aktivnom uglju $F A$ - filter adsorber, $R S V$ - reducir stanica za vazduh, $M S-$ monostat, I1, I2 - ispiralice za $\mathrm{H}_{2} \mathrm{SO}_{4}, \mathrm{KS} 1, \mathrm{KS} 2, \mathrm{KS} 3$ - kolone sa silikagelom, K1, K2 - kapilari, DM1, DM2 - diferencijalni manometar, S1, S2, S3 - spirale, $M$ - mešač, 13, $14-$ ispiralice benzina, SC1, SC2, SC3 ispitne cevi, TRVK - termostatiranje 
toplote (S1 i S2) dostiže potrebnu temperaturu od $20^{\circ} \mathrm{C}$.

Desna grana struje vazduha zasićava se parama benzina $\mathrm{kroz}$ ispiralice (I3 i I4) koje su napunjene benzinom i meša se sa levom granom struje vazduha $u$ mešalici $(M)$. Nakon mešanja, vazduh zasićen parama benzina do željene vrednosti propušta se kroz adsorpcione cevi (SC1, SC2 i SC3) koje su ispunjene sa $0,5 \mathrm{~g}$ uzorka aktivnog uglja. Neizreagovani deo benzina uklanja se iz struje vazduha kroz filter adsorber (FA2) pre nego što se vazduh ispusti u okolinu.

Kroz adsorpcione cevi propušta se smeša para benzina i suvog vazduha podešavanjem relativnog pritiska $u$ intervalu $10^{-2}$ do 1 . Relativni pritisak menja se promenom odnosa protoka čistog vazduha i vazduha zasićenog benzinom pomoću slavina na meračima protoka.

Uzorak od 0,5 g aktivnog uglja granulacije od 0,71 do $1 \mathrm{~mm}$, osušen na $150 \pm 5^{\circ} \mathrm{C}$, postavljen je $u$ ispitnu cev. Adsorpcija benzina obavljana je u granicama parcijalnog pritiska od 0,06 do 1,0 .
$\mathrm{Za}$ ispitivanje vremena zaštite formirana je aparatura koja je šematski prikazana na slici 2 .

Parametri ispitivanja su:

- protok vazduha kontaminiranog benzinom $50 \mathrm{dm}^{3} / \mathrm{min}$; $20^{\circ} \mathrm{C}$

- temperatura struje vazduha $50 \%$

- ulazna koncentracija benzina $0,1 \%$ zap. (1000 ppm);

$180 \mathrm{~cm}^{3}$;

— zapremina sloja aktivnog uglja

- masa aktivnog uglja $60 \mathrm{~g}$.

Prečišćavanje vazduha, vlaženje, merenje protoka i temperature obavljano je u primarnoj grani aparature podešavanjem protoka, temperature i vlažnosti vazduha, poštujući definisane uslove.

Doziranje benzina ostvarivano je propuštanjem vazduha kroz ispiralicu ispunjenu benzinom. Provera koncentracije benzina u struji vazduha obavljana je adsorpcionom metodom.

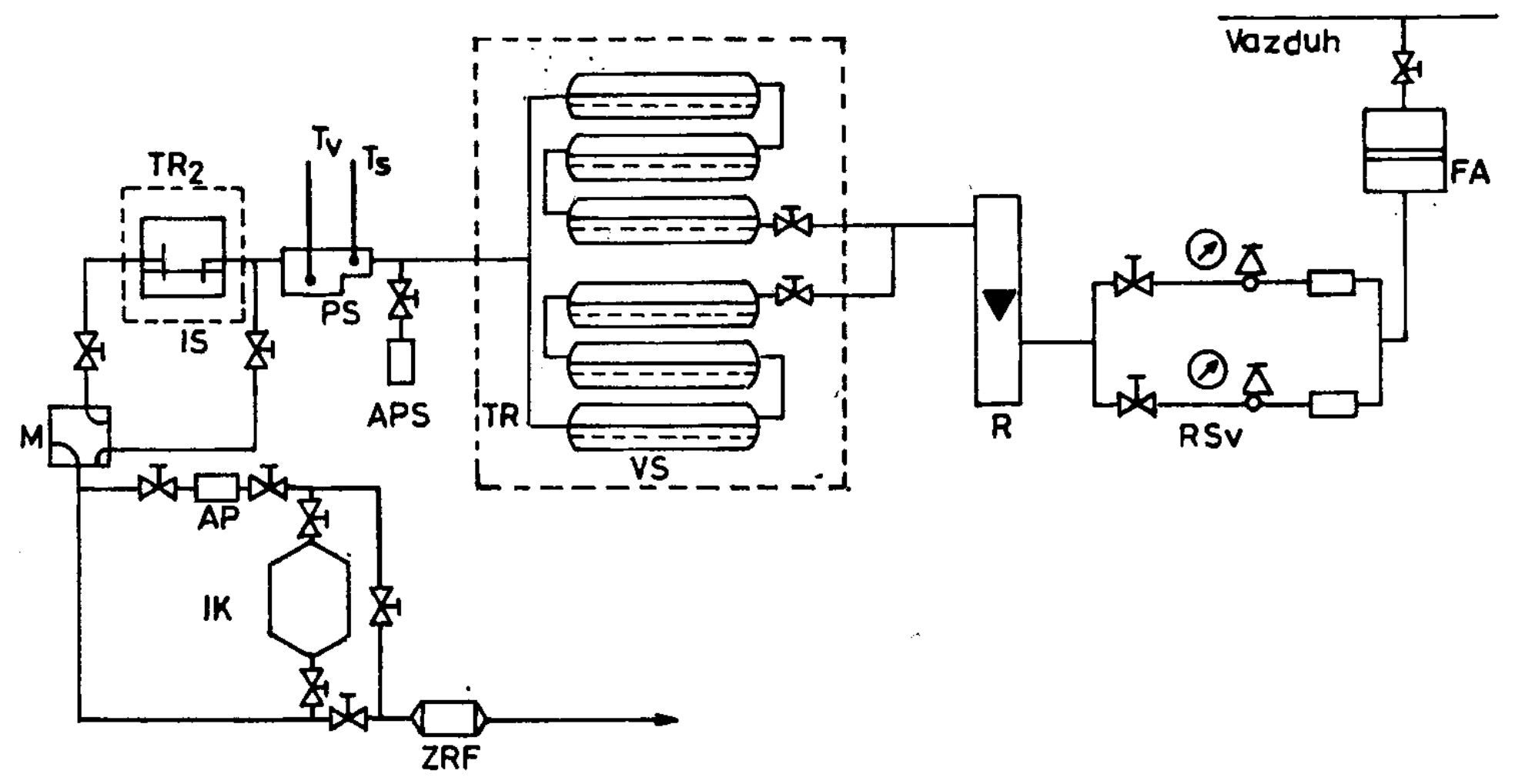

Sl. 2 - Aparatura za ispitivanje vremena zaštite sloja aktivnog uglja na pare benzina IS - isparivač benzina, TR2 - sekcija za termostatiranje, $R-$ rotametar, APS automatski psihrometar, $P S$ - psihrometar, FA - filter adsorber, $R S V$ - reducir za vazduh, $M$ - mešač, AP - adsorpciona patrona, IK - ispitna komora, ZRF zaštitni respiratorni filter 


\section{Rezultati ispitivanja $\mathbf{i}$ diskusija}

Dobijeni rezultati adsorpcionog kapaciteta u uslovima do zasićenja aktivnog uglja parama benzina, pri različitim parcijalnim pritiscima (koncentracijama), prikazani su u tabeli 2 i na dijagramima (izoterme adsorpcije) na slici 3 .

Upoređenjem kapaciteta adsorpcije na izotermi adsorpcije za aktivni ugalj $\mathrm{K}$ i $\mathrm{R}$ uočava se razlika koja je posledica razlike karakteristika ove

Tabela 2

Adsorpcioni kapacitet aktivnog uglja

\begin{tabular}{|c|c|c|}
\hline \multirow{2}{*}{$\begin{array}{c}\text { Parcijalni pri- } \\
\text { tisak (P/Po) }\end{array}$} & \multicolumn{2}{|c|}{$\begin{array}{c}\text { Adsorpcija benzina } \\
\text { a (g/g) }\end{array}$} \\
\cline { 2 - 3 } & $\begin{array}{c}\text { aktivni } \\
\text { ugalj } \mathrm{R}\end{array}$ & $\begin{array}{c}\text { aktivni } \\
\text { ugalj } \mathrm{K}\end{array}$ \\
\hline 0,06 & 0,1824 & 0,3080 \\
\hline 0,1 & 0,1906 & 0,3402 \\
\hline 0,17 & 0,1996 & 0,3476 \\
\hline 0,30 & 0,2208 & 0,3638 \\
\hline 0,50 & 0,2340 & 0,3720 \\
\hline 0,70 & 0,2558 & 0,3846 \\
\hline 0,90 & 0,2730 & 0,3920 \\
\hline
\end{tabular}

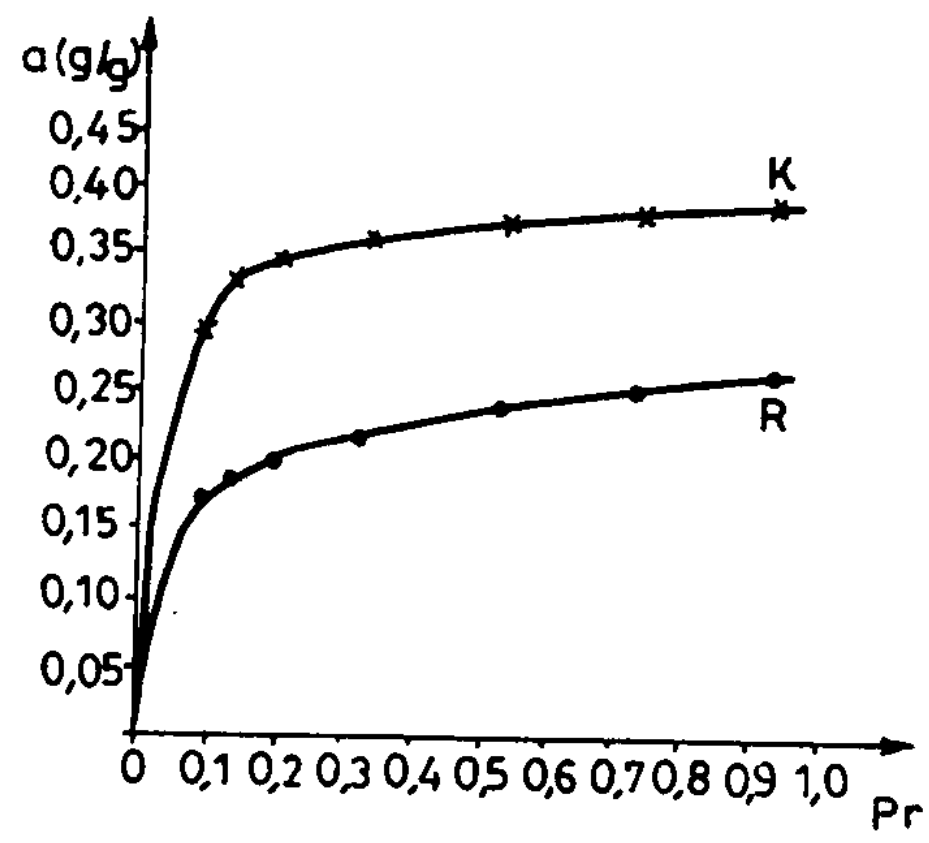

Sl. 3 - Izoterma adsorpcije benzina na aktivnom uglju $R$ i $K$ dve vrste aktivnih ugljeva. Iz karakteristika (tabela 1) vidi se da je indeks benzina (merenjem adsorpcione mase pare benzina u smeši sa vazduhom) za aktivni ugalj $\mathrm{K}$ minimalno $35 \%(0,35$ g/g), a u praksi se kreće od 42 do $45 \%$ $(0,42$ do $0,45 \mathrm{~g} / \mathrm{g})$. Indeks benzina $\mathrm{u}$ istim uslovima za aktivni ugalj $R$ je minimalno $33 \%(0,33 \mathrm{~g} / \mathrm{g})$, a obično od 35 do $36 \%(0,35$ do $0,36 \mathrm{~g} / \mathrm{g})$.

Specifična površina aktivnog uglja KCS po BET metodi je 1150 do 1200 $\mathrm{m} / \mathrm{g}$.

Pored ovih pogodnijih karakteristika aktivnog uglja $\mathrm{K}$, bolji adsorpcioni kapacitet je posledica i njegovih strukturnih karakteristika (raspodela i veličina pora). Ovakve adsorpcione i strukturne karakteristike pogoduju adsorpciji komponenata benzinskih para za ispitivane vrste benzina. Razvijena mikroporoznost ove vrste aktivnog uglja pogoduje adsorpciji tipičnih komponenata iz smeše benzina. Tipični sastav benzina je sa dominantnim sadržajem nezasićenih parafina ili alkana (metan, n-butan, izobutan), nezasićenih olefina ili alkena (etilen, butan-1, 2-metil-butan-1), cikloparafina ili cikloalkana (ciklobutan) i aromatičnih jedinjenja (benzin, toluen).

S obzirom na to da je aktivni ugalj $\mathrm{K}$ pogodniji za adsorpciju para benzina, podvrgnut je ispitivanju krive probijanja do zasićenja. Vreme zaštite i kapacitet adsorpcije za različite procente probijanja u dinamičkim uslovima prikazani su u tabeli 3 i na slici 4 .

Tabela 3

Vreme zaštite i kapacitet adsorpcije

\begin{tabular}{|c|c|c|}
\hline $\begin{array}{c}\text { P(Cx/Co) } \\
(\% / 0 \text { zap. })\end{array}$ & $t$ (min) & We (g/g) \\
\hline 1 & 50 & 0,13 \\
\hline 10 & 61 & 0,15 \\
\hline 50 & 74 & 0,17 \\
\hline 90 & 87 & 0,22 \\
\hline 99 & 122 & 0,30 \\
\hline
\end{tabular}




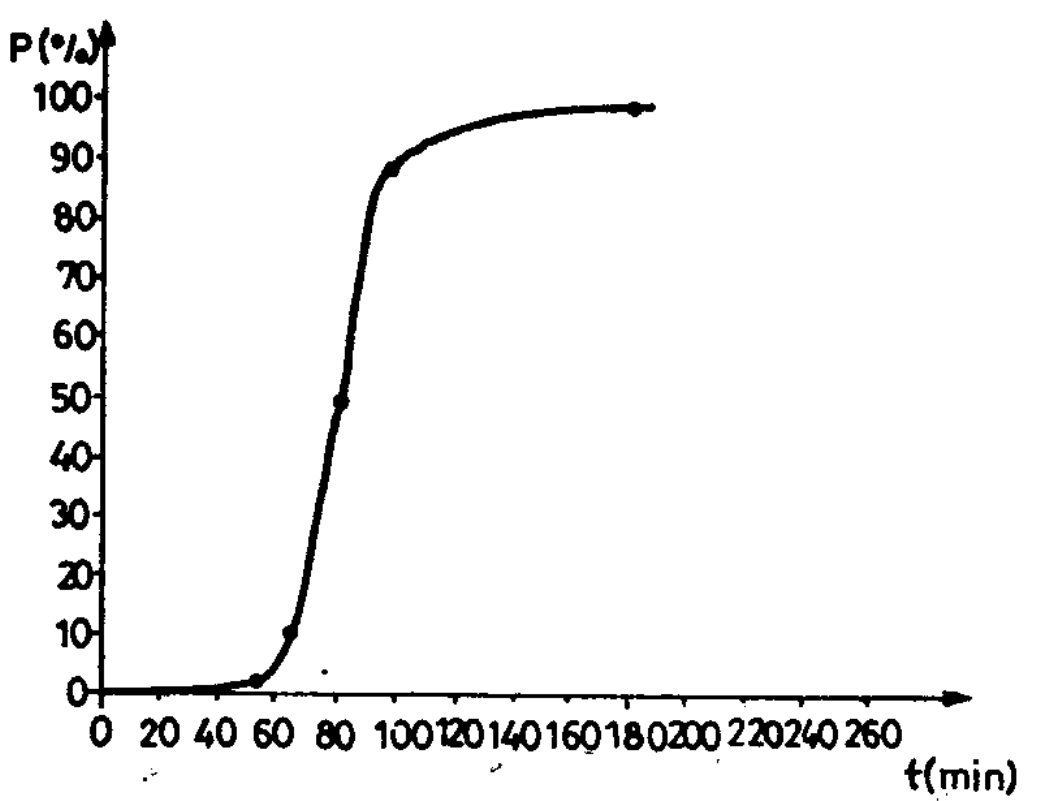

Sl. 4 - Kriva probijanja za benzin

\section{Zaključak}

Rezultati eksperimentalnog ispitivanja adsorpcionog kapaciteta aktivnog uglja K (aktivirana ugljenisana

\section{Literatura:}

[1] Tomić, V.: VII naučni skup „Covek i radna sredina«, Niš, 1988.

[2] Tomić, V.: Savetovanje o proizvodnji i upotrebi zaštitnih sredstava, Kruševac, 1989.

[3] Tomić, V.: XXII savetovanje »Zaštita vazduha«, Beograd, 1994.

[4] Tomić, V.: Naučni skup RPT 94, Niš, 1994. kokosova ljuska) na pare benzina pokazali su da ova vrsta aktivnog uglja može da bude praktično sredstvo za kontrolu emisije isparljivih ugljovodonika u postupcima gde se primenjuje korišćena vrsta benzina.

Bez obzira na to što je kapacitet adsorpcije pri zasićenju (izoterma adsorpcije) duplo veći od kapaciteta pri proboju (izlazna koncentracija $\mathrm{P}=10 \%$ na krivi probijanja), u praktičnoj primeni radi maksimalnog iskorišćenja sloja, najcelishodnije je ugraditi najmanje dva redno povezana filtera.

U svim uslovima gde dolazi do emisije para benzina moguće je primeniti filter za zaštitu organa za disanje, kao i filtere za zaštitu radne i životne sredine na bazi ispitivane vrste aktiv. nog uglja.

[5] Nikolić, D.: Magistarski rad FZNR, Niš, 1992.

[6] Nikolić, D.: Dinamika adsorpcije u filterima zaštite SC ABHO Kruševac, 1995.

[7] Tomić, V.: Magistarski rad FZNR, Niš, 1992.

[8] Nikolić, D., Biočanin, R.: Aktivni ugalj u funkciji NHB zaštite, Bilten SC ABHO, Kruševac, 1995. 